\title{
KONSEP PENDIDIKAN BAGI PEREMPUAN MENURUT DEWI SARTIKA
}

YENI SULISTIANI*

SDN Cisalak

Pedagogik SPs Universitas Pendidikan Indonesia

\section{LUTFATULATIFAH}

IAIN Syekh Nurjati Cirebon

\author{
yeni.tian@gmail.com
}

uul@syekhnurjati.ac.id

- Received: 25 April 2020 • Accepted: 26 Mei 2020

-Published online: 30 Desember 2020

\begin{abstract}
:
Tulisan ini bertujuan mendeskripsikan konsep pendidikan bagi perempuan menurut Dewi Sartika. Metode penelitian yang digunakan adalah library research. Pendidikan menurut Dewi Sartika adalah ilmu atau alat untuk menata, mengubah, dan memajukan segala perkara ke arah yang lebih baik, termasuk anak didik. Hasil guna dari tulisan ini dapat dijadikan batu-batu landasan untuk memahami bagaimana konsep pendidikan dalam pemikiran Dewi Sartika, serta pemikiran untuk mengembangkan penelitan lebih lanjut, baik mengenai Dewi Sartika, maupun tentang konsep pendidikan tokoh lainnya yang akan memperkaya khazanah keilmuan, terutama bagi praksis pendidikan.
\end{abstract}

Kata kunci: Pendidikan; Dewi Sartika; Perempuan.

\begin{abstract}
This paper aims to describe the concept of education for women according to Dewi Sartika. The research method used is library research. According to Dewi Sartika, education is a knowledge or tool to organize, change, and advance all things for a better direction, including students. The useful results of this paper can be used as foundation stones to understand how the concept of education is in Dewi Sartika's thoughts, as well as thoughts to develop further research, both regarding Dewi Sartika, as well as about the concept of education of other figures that will enrich scientific treasures, especially for practical education.
\end{abstract}

Keywords: education; women; Dewi Sartika.

*Corresponding Yeni Sulistiani, Email: yeni.tian@gmail.com 


\section{A. PENDAHULUAN}

Berbicara masalah emansipasi, masyarakat Indonesia akan langsung mengingat sosok Kartini. Pemikiran Raden Ajeng Kartini (1879-1904), putri Bupati Jepara yang mengenyam pendidikan Belanda, prihatin dengan kondisi perempuan Jawa yang terkungkung oleh ikatan-ikatan kultural dan struktural. Surat menyuratnya dengan seorang perempuan Belanda yang kemudian diterbitkan menjadi buku telah menginspirasi dan mendorong kaum perempuan di negeri ini untuk meraih hak-hak mereka. Dalam proses emansispasi tersebut, Kartini sebagai inspirator tetap berpijak pada pandangan yang menjaga keseimbangan antara pendidikan sekuler dan keagamaan sebagai kunci sukses kemajuan kaum perempuan (Rosadi, 2011). Nama Kartini sudah tidak asing lagi di telinga masyarakat Indonesia, bahkan tanggal lahirnya diabadikan dan diperingati sebagai hari Kartini oleh seluruh kalangan lapisan masyarakat. Kartini merupakan intelektual produk Politik Etis pada awal abad ke-19 telah sejak lama memperjuangkan kesetaraan gender yang dikenal dengan perjuangan emansipasi. Refleksi kritis Kartini tentang keadaan kaum wanita pada zamannya merupakan embrio tumbuhnya nasionalisme meskipun sifatnya masih samar (Sudrajat, 2007). Selain Kartini ada tokoh perempuan lainnya, yang barangkali tidak banyak orang tahu bagaimana perjuangannya dalam memperjuangkan hak-hak wanita, terutama pendidikan. Lebih dari Kartini, dia tidak hanya mengungkapkan pemikirannya, tetapi juga mengaktulisasikan pemikirannya dengan membangun sekolah khusus bagi perempuan. Dia adalah Raden Dewi Sartika. Bahkan sekelas pujangga terkenal, yakni WS Rendra (dalam Daryono, 2008) mengatakan dibanding dengan Raden Ajeng Kartini, keduanya sama penting sebagai pelopor kesadaran perempuan akan emansipasi manusia pada umumnya dan perempuan pada khususnya. Menurut Daryono (2008) agaknya Raden Ajeng Kartini rupanya tidak memiliki naluri seorang aktifis. Ia lebih tepat sebagai sastrawan dari sastra surat. Nilai sastra yang terkandung dalam surat-suratnya sangat tinggi. Menguasai metaphora yang mencerminkan kedalaman penghayatan batin dan ketelitian dalam pengamatan terhadap lingkungan. Surat-suratnya adalah kumpulan esai yang indah.

Dewi Sartika lahir di Bandung, 4 Desember 1884. Beliau adalah tokoh perintis pendidikan untuk kaum perempuan, diakui sebagai Pahlawan Nasional oleh 
Yeni Sulistiani, Lutfatulatifah

Pemerintah Indonesia tahun 1966. Dewi Sartika dilahirkan dari keluarga priyayi (menak) Sunda, Nyi Raden Rajapermas dan Raden Somanagara. Dewi Sartika mendirikan Sakola Istri (yang kelak berubah nama menjadi Sakola Kautamaan Istri, dan sekarang menjadi Sekolah Dewi Sartika), di mana ia pun menuangkan pemikirannya tentang bagaimana perempuan seharusnya dan seberapa penting pendidikan bagi perempuan. Ia menceritakan pula pendirian Sakola Kautamaan Istri dalam karya bukunya yang berjudul "Boekoe Kaotamaan Istri". Hingga akhir hayatnya, sekolah yang dibangun oleh Dewi Sartika terus berkembang. Di beberapa wilayah Pasundan bermunculan beberapa Sakola Istri, terutama yang dikelola oleh perempuan-perempuan Sunda yang memiliki cita-cita yang sama dengan Dewi Sartika. Pada tahun 1912 sudah berdiri sembilan Sakola Istri di kota-kota kabupaten (setengah dari seluruh kota kabupaten se-Pasundan). Memasuki usia ke-sepuluh, tahun 1914, nama sekolahnya diganti menjadi Sakola Kautamaan Istri (Sekolah Keutamaan Perempuan). Kota-kota kabupaten wilayah Pasundan yang belum memiliki Sakola Kautamaan Istri tinggal tiga/ empat, semangat ini menyeberang ke Bukittinggi, di mana Sakola Kautamaan Istri didirikan oleh Encik Rama Saleh (Daryono, 2008; Wiriatmaja, 1985; Rosidi, 2009; Bayu dan Sri, 2017).

Dari penjelasan tersebut dapat dikatakan bahwa pemikiran R. Dewi Satika berkontribusi untuk Indonesia, terutama pendidikan dan kaum wanita. Namun bangsa Indonesia belum memahami betul, bahkan mungkin sebagian tidak mengenal bagaimana konsep perempuan dan pendidikan bagi perempuan dalam perspektif Dewi Sartika. Oleh sebab itu, konsep pendidikan menurut R. Dewi Sartika perlu dikaji untuk generasi mendatang. Hal ini diperlukan agar dapat diketahui dan diuraikan bagaimana konsep pendidikan menurut R. Dewi Sartika, apakah konsep pendidikan menurutnya ini diperlukan pada generasi ini dan generasi mendatang.

\section{B. METODOLOGI PENELITIAN}

Dalam penelitian ini menggunakan metode Library research atau riset pustaka maksudnya adalah penelitian yang dilakukan hanya berdasarkan atas karya tertulis seperti buku, ensiklopedia, jurnal, kamus dan majalah (Harahap, 2014). Dalam penelitian ini sama dengan penelitian lainnya yang memerlukan rumusan masalah, landasan teori, analisis data dan pengambilan kesimpulan. Akan tetapi sumber dan 
Yeni Sulistiani, Lutfatulatifah

metode pengumpulan data dengan mengambil data dipustaka dengan membaca, mencatat, dan mengelolah bahan penelitian. Sehingga tidak perlu mengumpulkan data dengan turun ke lapangan dan bertemu dengan responden.

\section{HASIL DAN PEMBAHASAN}

Dari hasil penelitian yang telah dilakukan menghasilkan dua analisis besar terkait pandangan pendidikan Dewi Sartika itu dapat berdiri. Pertama yakni dilihat dari Tinjauan Filosofis dan Tinjauan Teoretis. Lebih lanjut akan dibahas dibawah ini.

\section{Tinjauan Filosofis}

\section{a. Hakikat Manusia}

Melalui sejarah hidupnya dalam Daryono (2008), Wiriatmaja (1985), Rosidi (2009), serta Bayu dan Sri (2017) kita dapat melihat sosok Dewi yang dari kecil menunjukkan keminatannya terhadap dunia pendidikan. Ia sering mengajari dan membacakan surat gadis-gadis remaja. Hal tersebut telah menimbulkan kesadaran Dewi akan keadaan yang menyedihkan dari kaumnya. Gadis-gadis yang notabene berasal dari gologan bangsawan merupakan lapisan terpandang dan di masa depan akan mendampingi suami sebagai istri pemimpin di daerah, dalam kenyataannya mereka buta aksara dan kurang sekali dalam pengetahuan umum tentang dunia sekitarnya. Dewi harus menelan kepahitan terpisah dari orang tua dan saudaranya. Ibunya lebih memilih mengikuti suaminya dan meninggalkan Dewi serta saudarasaudaranya. Dorongan terbesar dalam mendirikan sekolah untuk wanita adalah ketika ia melihat ibunya menderita saat ditinggal meninggal oleh ayahnya. Ibunya kembali dari perasingan tetapi ia seperti kehilangan arah dan tak berdaya.

Apabila kita amati dalam pemikirannya, kita dapat melihat bahwa Dewi dapat mendobrak sebuah ketabuan dalam sebuah lingkungan sosio budaya yang berkembang saat itu. Sejarah mencatat awalnya dalam persepsi masyarakat Jawa (Bayu dan Sri, 2017, hlm 5) disebutkan sebagai berikut “...wanita sering dimaknai dengan wani tata dan sekaligus wani nata. Dalam pengertian wani ditata, wanita (istri) wajib mendengarkan serta melaksanakan petuah-petuah yang baik dari guru laki (suami). Sementara dalam pengertian wani nata, wanita musti mampu memberikan pertimbangan atas pemikiran suami higga lahirlah keputusan yang arif demi kebaikan bersama dalam suatu keluarga. Terwujudnya simbiosis mutualisme antara 
wanita (istri) dengan pria (suami) yang akan menjadi kunci di dalam menciptakan stabilitas kehidupan di dalam berumah tangga." dari pernyataan tersebut kita dapat melihat dalam masyarakat Jawa, Indonesia, wanita dijunjung tinggi perannya, dia memiliki peran yang saling melengkapi satu sama lain dengan laki-laki, bahkan beberapa wanita diceritakan pernah menduduki peran sebagai ratu dan berkuasa atas suatu wilayah. Peran wanita yang teramat penting ini selaras dengan apa yang ditegaskan Bayu dan Sri (2017, hlm 6) sebagai berikut “...asumsi perihal wanita sekadar sebagai kanca winking (istri yang pekerjaannya cuma di dapur dan sumur), isi-sining omah (istri sebagai pelengkap dalam rumah tangga), atau partner seks tersebut sesungguhnya sangat bertentangan dengan kearifan Jawa." Namun seiring berjalannya waktu, terutama saat penjajahan oleh bangsa asing, seperti Belanda, hal tersebut mengalami pergeseran. Wanita tidak lagi dihargai, bahkan ia ditempatkan statusnya di bawah laki-laki. Perkawinan paksa, tidak diperbolehkannya dalam mengenyam pendidikan dan sebagainya adalah sebagian kecil diskriminasi yang dialami wanita (Helwig, 2007 dan Vredee-de, 2017). Dewi Sartika lahir dan tumbuh dalam kondisi sosio budaya yang seperti itu. Maka, kita dapat sebut Dewi Sartika sebagai salah satu tokoh yang pemikirannya dipengaruhi oleh feminisme. Feminisme merupakan doktrin, gerakan yang membela perluasan hak-hak dan perempuan dalam masyarakat. Sebuah istilah feminis digunakan sebagai ungkapan umum dalam bahasa Inggris, kata-kata seperti womanism, the woman movement, atau woman questions telah digunakan terlebih dahulu (Mohamad, 2013). Secara umum feminisme mengakui bahwa perbedaan seksual adalah poros organisasi sosial yang fundamental dan tak dapat direduksi. Feminis terutama memberikan perhatian kepada jenis kelamin sebagai suatu prinsip pengatur kehidupan sosial yang dipenuhi oleh relasi kekuasaan yang menyubordinasi perempuan di bawah laki-laki (Saefuddin, 2017). Feminisme menurut dapat dirumuskan sebagai keyakinan, gerakan dan usaha untuk memperjuangkan kesetaraan posisi perempuan dan lakilaki dalam masyarakat yang bersifat patriarkis (masyarakat yang mengutamakan kepentingan laki-laki di atas kepentingan perempuan) (Arivia 2003; Amin, 2013; Komang, 2013; dan Amin, 2015).

Manusia, menurut Dewi Sartika baik laki-laki maupun perempuan, tidak cukup hanya baik saja, tetapi juga harus memiliki pemahaman, kecakapan, keahlian 
Yeni Sulistiani, Lutfatulatifah

untuk bekal hidupnya, seperti apa yang diungkapkannya sebagai berikut " Tetapi manusia itu, laki-laki ataupun wanita, tidak cukup hanya baik saja, tetaapi harus juga memiliki pengetahuan dan kecakapan buat mencari jalan hidup pada waktu tak ada yang memberi nafkah buat menjaaga keselamatan, menghindari marabhaya dan lain sebagainya." (Sartika, 1912).

Pendidikan bagi perempuan teramat penting. Pemikiran Dewi Sartika juga sangat dipengaruhi oleh pemikiran Sundanisme. Hal ini tidak terlepas dari lingkungan dan silsilah keturunannya sebagai orang Sunda. Pemikiran dan gaya bahasa yang ia tuangkan dalam tulisan-tulisan tangannya banyak menggunakan istilah-istilah dan peribahasa-peribahasa sunda. Salah satu istilah Sunda yang ia gunakan dalam mengemukakan pemikirannya tentang pendidikan dalam tujuannya untuk membentuk anak didik yang cageur bageur, cepet bener (sehat, baik, cekatan dan benar). Kata-kata tersebut hampir mirip dengan istilah filosofi nilai-nilai etos dan watak Sunda itu ada lima, yakni cageur, bageur, bener, singer, dan pinter yang sudah lahir sekitar zaman Salakanagara dan Tarumanagara (sejarah Sunda). Sehingga dalam memahami pemikiran Dewi Sartika diperlukan juga memahami filsafat sunda.

\section{b. Pandangan Dunia}

Dunia dan realitasnya, dalam tulisannya Dewi berkali-kali menekankan persamaan hak yang harus dimiliki oleh laki-laki dan perempuan. Dalam sebuah bangsa, agar bertambah maju, maka kaum wanita harus maju pula, pintar seperti kaum laki-laki. Kaum wanita itu akan menjadi ibu. Mereka yang paling dahulu mengajarkan pengetahuan kepada manusia, yaitu kepada anak-anak mereka, lakilaki maupun perempuan.

\section{c. Nilai-nilai Kehidupan}

Nilai-nilai kehidupan yang berarti di dunia ini menurut Dewi Sartika adalah adanya persamaan hak antara laki-laki dan wanita, terutama dalam mengenyam bangku pendidikan. Menurutnya, perempuan akan dan harus bernilai lebih daripada sebuah meubel di rumah. Begitu juga dengan bangsawan dan abdi semuanya harus bersinergi dalam kehidupan. 
Yeni Sulistiani, Lutfatulatifah

\section{Tinjauan Teoritis}

\section{a. Konsep Pendidikan}

Konsep adalah suatu ide yang mengkombinasikan beberapa elemen ke dalam suatu gagasan tunggal, disusun dengan kata, symbol, atau tanda (Chaplin, 2014, hlm 1). Bruner ( Joyce \& Weil, 2003, hlm 164-170; Prabhakaram, 2006; Shiddiqui \& Khan, 2007), konsep terdiri dari lima elemen yaitu nama, contoh, atribut, nilai atribut, dan aturan. konsep merupakan hasil pemikiran manusia yang diperoleh melalui fakta-fakta dan peristiwa yang dinyatakan dalam definisi dan dapat digunakan untuk memecahkan masalah dalam kehidupan sehari-hari. Konsep diperoleh ketika unsur-unsurnya diidentifikasi dan dipelajari kebenarannya. Unsurunsur konsep tersebut ialah: (1) nama (label yang memberikan kategori), (2) atribut (karakteristik/ sifat/ ciri-ciri objek, ada dua tipe atribut yang esensial dan nonesensial), (3) contoh-contoh (contoh positif di dalamnya terdapat atribut yang nonesensial, dengan contoh ini bisa disimpulkan apa pengertian konsep tersebut), dam (4) definisi (pernyataan khusus dari atribut suatu konsep, berupa simpulam dari penemuan dalam pencarian atribut-atribut esensial dan nonesensial dari contoh positif dan contoh negatif, berupa hubungan atribut-atribut yang esensialnya).

\section{b. Hakikat Pendidikan}

Sebuah pernyataan yang lazim diperbincangkan bahwa hakikat pendidikan adalah memanusiakan manusia. Mudyahardjo (2014) membagi pengertian pendidikan ke dalam tiga cara, yakni definisi maha luas, definisi sempit, dan definisi alternatif atau luas terbatas. Dalam definisi maha luas pendidikan adalah hidup itu sendiri dan berlangsung sepanjang hidup. Pengertian yang maha luas ini selaras dengan apa yang diungkap Henderson (dalam Sadulloh, 2017). Definisi sempit mengartikan pendidikan adalah sekolah, sedangkan dalam definisi alternatif pendidikan adalah usaha sadar yang dilakukan oleh keluarga, masyarakat, dan pemerintah, melalui kegiatan bimbingan, pengajaran, dan/ atau latihan yang berlangsung di sekolah dan luar sekolah sepanjang hayat. Namun jika kita tarik benang merah dari ketiganya, ada hal yang sama, yakni bahwa pendidikan memiliki tujuan untuk mengembangkan potensi peserta didik itu sendiri. Pendidikan bisa dianggap sebagai proses yang terjadi secara sengaja, direncanakan, didesain, dan diorganisasi berdasarkan aturan yang berlaku terutama perundang-undangan yang 
Yeni Sulistiani, Lutfatulatifah

dibuat atas dasar kesepakatan masyarakat. Pendidikan sebagai sebuah kegiatan dan proses aktivitas yang disengaja merupakan gejala masyarakat ketika sudah mulai disadari pentingnya upaya untuk membentuk, mengarahkan, dan mengatur manusia sebagaimana dicita-citakan masyarakat. Seperti yang termaktub dalam Undang-Undang Nomor 20 Tahun 2003 tentang Sistem Pendidikan Nasional, pendidikan nasional berfungsi mengembangkan kemampuan dan membentuk watak serta peradaban bangsa yang bermartabat dalam rangka mencerdaskan kehidupan bangsa, yang bertujuan untuk berkembangnya potensi peserta didik agar menjadi manusia yang beriman dan bertakwa kepada Tuhan Yang Maha Esa, berakhlak mulia, sehat, berilmu, cakap, kreatif, mandiri, dan menjadi warga negara yang demokratis serta bertanggung jawab. Pendidikan merupakan bagian penting dari kehidupan manusia yang tak pernah bisa ditinggalkan. Pendidikan juga merupakan salah satu sarana terpenting dalam usaha pembangunan sumber daya manusia dan penanaman nilai-nilai kemanusiaan, yang pada gilirannya akan menciptakan suasana dan tatanan kehidupan masyarakat yang beradab dan berperadaban (Kamal, 2016).

Tidak ada istilah pendidikan dalam karya tulis Dewi Sartika. Ia hanya mengungkap tentang pengajaran. Pengajaran yaitu ilmu atau alat untuk menata, mengubah, dan memajukan segala rupa atau perkara ke arah yang lebih baik Serupa halnya dengan kayu kasar dapat diperhalus dengan serut, pohon kurus dapat dipersubur, manusia buruk dapat dididik, yang bodoh harus diajar; maka dari itu dengan pengajaran dapat jadi lebih baik, baik akhlaknya, baik pula laku dan kehidupannya (Sartika, 1912, hlm 7). Menurutnya manusia atau bangsa yang maju adalah bangsa yang baik laki-lakinya maupun perempuannya cerdas (bukan hanya secara kognitif, tetapi juga afektif, akhlak dan budinya baik), bangsawan maju, rakyat pun subur tenteram.

Sekolah itu modal hidup, sebab selain pelajaran pokok, anak-anak itu diberikan pelajaran: kebersihan, tatakrama, berbicara fasih dan sopan, disiplin, taat, gembira, baik dan suci hati, hemat, serta berpikir atau memilih. Di Sekolah Istri Bandung ini ditambah pula dengan tiga keahlian lain untuk saat ini, yakni keterampilan wanita, rumah tangga dan memasak. Sedangkan untuk ke depannya diagendakan akan ada pelajaran membatik. Anak didik diharapkan sehat, baik, 
Yeni Sulistiani, Lutfatulatifah

cekatan dan benar (cageur bageur, cepet bener) baik laki-laki maupun wanita. Dalam proses belajar mengajar, isi pendidikan yang diberikan tidak hanya kemampuan membaca, menulis dan berhitung, tetapi juga berbagai macam keterampilan wanita seperti memasak, mengurus anak, membatik, merenda, dan lain-lain.

\section{c. Proses Pendidikan}

Proses pendidikan meliputi komponen-komponen pendidikan yang terdiri dari pendidik, peserta didik/ anak didik, alat pendidikan, situasi pendidikan, dan lingkungan pendidikan. Menurut Dewi guru yang utama harus memiliki kasih sayang, ucap dan tingkah lakunya selaras, tahu tata karma karena seorang guru akan menjadi teladan bagi siswa. Menurut Dewi Sartika metode atau usaha yang harus dilaksanakan dalam mendidik anak ada dua macam, yaitu menasehati dan memberi contoh. Manusia, baik laki-laki maupun perempuan, tidak cukup hanya baik saja, tetapi juga harus memiliki pemahaman, kecakapan, keahlian untuk bekal hidupnya. Pendidikan bagi perempuan juga teramat penting. Dewi mengungkap bahwa seorang wanita harus mendidik anak agar menjadi anak yang baik. Usaha atau syarat agar anak itu sesudah besarnya menjadi orang baik ialah sejak kecil harus sehat. Anak sehat menurut dokter yaitu tidak banyak penyakit di dalam tubuhnya, tidak lemah panca inderanya, tajam penglihatan, tajam penciuman, tajam pendengaran, cerdas, dan terbuka hatinya. Penyakit ada dua macam, yaitu penyakit karena pembawaan dan penyakit adat kebiasaan. Sifat anak berdasarkan pula atas pergaulannya dan pendidikannya. Penyakit tersebut dapat dicegah dan diobati oleh usaha dan pemeliharaan yang baik. Jika anak itu dijaga, dididik dan diperhatikan, maka penglihatan dan pilihannya tentu akan berbeda dengan anak yang tidak baik penjagaan dan pendidikannya. Sebuah peribahasa mengatakan, “ingatan yang terang benderang atau hati yang terbuka terdapat pada badan yang sehat".

Dalam karyanya Dewi menuangkan pemikirannya mengenai bagaimana standar lulusan pendidikan, yaitu "nu bisa hirup". Artinya hasil pendidikan harus mampu membentuk manusia yang bisa hidup, menghadapi tantangan zaman. Bagi Dewi sebuah kebahagian ketika ia melihat lulusan Sakola Istri (sekolah yang Ia bangun) sudah mampu berjualan, berwirausaha, dan membantu orang tuanya agar orang- 
Yeni Sulistiani, Lutfatulatifah

orang pun dapat melihat dan mengerti akan maksud anak-anak perempuan disekolahkan.

Salah satu contoh konsep ialah pendidikan. Konsep pendidikan dapat didefinisikan sebagai ide-ide atau pemikiran-pemikiran tentang pendidikan (Muhajir, 2012). Konsep pendidikan menurut Tafsir (2012) setidaknya terdiri dari empat komponen, yakni tujuan pendidikan, proses pendidikan, evaluasi pendidikan dan kendala pendidikan. Sehingga dalam meneliti konsep pendidikan, harus memerhatikan hal-hal tersebut.

\section{KESIMPULAN}

Raden Dewi Sartika merupakan salah satu tokoh pahlawan yang berjuang dalam kemajuan pendidikan perempuan dari Jawa Barat. Menurutnya pendidikan bagi wanita teramat penting. Wanita adalah pilar utama dalam membangun generasi Bangsa dikarenakan wanita akan mendidik anak-anaknya kelak menjadi anak yang baik. Anak yang baik yang dimaksudkan Dewi Sartika adalah anak yang sehat secara fisik, psikis, berintelektual, beretika, dan memiliki kecakapan untuk bekal hidupnya. Pada masanya saat wanita dianggap sebagai posisi "kedua", Dewi Sartika memikirkan jauh ke depan pandangannya akan pendidikan wanita. Pendidikan baginya adalah ilmu atau alat untuk menata, mengubah, dan memajukan segala perkara ke arah yang lebih baik, termasuk anak didik di sini. Metode pendidikan yang terbaik menurutnya adalah teladan dari guru itu sendiri, maka guru memiliki peranan teramat proses pendidikan.

Apa yang telah dilakukan Dewi Sartika pada masanya adalah sebuah gerakan feminis karena mampu mendobrak ketabuan yang saat itu dianggap tidak biasa. Pemikiran Dewi Sartika tentang pendidikan bagi wanita menginspirasi banyak orang yang kemudian juga turut mengembangkan Sakola Istri. Konsep pendidikan yang dikemukakan oleh Dewi Sartika yang mengatakan bahwa perempuan harus memiliki kecakapan untuk bekal hidupnya sangatlah selaras dengan masa kini. Dari gagasan-gagasannya itu, dapat kita ketahui bahwa Dewi Sartika adalah seorang pemikir, aktivis dan feminis yang berpandangan jauh ke depan untuk kemajuan bangsanya, terutama kaum perempuan. 


\section{UCAPAN TERIMAKASIH}

Dr. Babang Robandi, M.Pd, Dr. Pupun Nuryani, M.Pd, Dr. H. Y. Suyitno, M.Pd yang telah membantu penulisan karya ilmiah ini.

\section{REFERENCES}

Amin, Saidul. (2013). Feminisme dan Islam. Kafa'ah: Jurnal Ilmiah Kajian Gender, 123143. Doi: $10.15548 / j k . v 3 i 2.38$

. (2015). Filsafat Feminisme (Studi Kritis terhadap Pembaharuan Perempuan di Dunia Barat dan Islam). Pekanbaru: Asa Riau.

Arikunto, S dan Jabar, C. S. (2009). Evaluasi Program Pendidikan: Pedoman Teoretis Praktis bagi Mahasiswa dan Praktisi Pendidikan. Jakarta: Bumi Aksara.

Arivia, Gadis. (2003). Filsafat Berperspektif Feminis. Jakarta: Yayasan Jurnal Perempuan (YJP).

Bayu Adji, Krishna dan Sri Wintala Ahmad. (2017). Istri-Istri Raja di Tanah Jawa. Yogyakarta: Araska.

Chaplin, J. P. (2014). Kamus Lengkap Psikologi. (D. K. Kartono, Penerj.). Depok: PT RajaGrafindo Persada.

Dahar, R.W. (1989). Teori-teori Belajar. Jakarta: Erlangga.

Daryono, Yan. (2008). Raden Dewi Sartika Sang Perintis. Bandung: Yayasan AWIKA \& PT.Grafitri Budi Utami.

Harahap, N. (2014). PENELITIAN KEPUSTAKAAN. Iqra, 8(01), 68-74.

Helwig, Tineke. (2007). Citra Kaum Perempuan di Hindia Belanda. Jakarta: Yayasan

Obor Indonesia.

Ibrahim, Tatang. (2018). Manajemen "Sekolah Kaoetamaan Istri" Raden Dewi Sartika dalam Meningkatkan Keterampilan Kaum Wanita Sunda. Jurnal Manajemen Pendidikan Islam Al-Idarah, Vol 3, No 1, 18-23.

Joyce, B., \& Weil, M. (2003). Models of Teaching. New Delhi: Jy Print Pack Private.

Joyce, W., \& Calhoun. (2009). Models of Teaching (Eighth Edition): Model model Pengajaran (Edisi Delapan), terj. Achmad Fawaid dan Ateilla Mirza. Yogyakarta: Pustaka Pelajar.

Kamal, Mustofa. (2016). Restrukturisasi Pendidikan menuju Bangsa Berkarakter. Jurnal Madaniyah: Terciptanya Insan Akademis Berkualitas \& Berakhlak Mulia, Vol 4, No 1, 35-44.

Komang, Ni Arie Suwastini. (2013). Perkembangan Feminisme Barat dari Abad ke Delapan Belas hingga Postfeminimse: Sebuah Tinjauan Teoritis. Jurnal Ilmu Sosial dan Humaniora, Vol 2, No 1, 198-208.

Mohamad, Hari Tohari. (2013). Feminisme Sunda Kuno (Studi Interpretasi Kritis Akulturasi Nilai-nilai Kesetaraan Gender Sunda-Islam dalam Carita Pantun Sri Sadana). Tesis. Universitas Pendidikan Indonesia. Tidak Diterbitkan.

Mudyahardjo, Redja. (2014). Pengantar Pendidikan Sebuah Studi Awal tentang Dasardasar Pendidikan pada Umumnya dan Pendidikan di Indonesia. Jakarta: Rajawali Press.

Muhajir, A. (2011). Ilmu Pendidikan Perspektif Kontekstual. Jogjakarta: Ar Ruzz Media. Mujib, A dan Mudzakkir, J. (2008). Ilmu Pendidikan Islam. Jakarta: Kencana 
Prabhakaram, K. S. (2006). Concept Attaintment Model in Mathematics Teaching. New Delhi: Discovery Publishing House.

Rosadi, Andri. (2011). Feminisme Islam: Kontekstualisasi Prinsip-Prinsip Ajaran Islam dalam Relasi Gender. Kafa'ah: Jurnal Ilmiah Kajian Gender, Vol 1, No 1, 1-12.

Rosidi, Ajip. (2009). Manusia Sunda. Bandung: PT Kiblat Buku Utama.

Sadulloh, U., dkk. (2007). Pedagogik. Bandung: Cipta Utama.

Saefuddin, Fahmi. (2017). Gender dan Eksistensialisme Sartre. Jurnal Studi Al-Qur'an; Membangun Tradisi Berfikir Qur'ani, Vol 13, No I, 95-118. Doi: doi.org/10.21009/JSQ.013.1.07

Sagala, S. (2006). Konsep dan Makna Pembelajaran untuk Membantu Memecahkan Problematika Belajar dan Mengajar. Bandung : CV Alfabeta.

Sartika, R. Dewi. (1912). Boekoe Kaoetamaan Istri. Bandung: A. C. NIX \& Co.

Shiddiqui, M. H., \& Khan, S. (2007). Models of Teaching: Theory and Research. New Delhi: APH Publishing Corporation.

Soetjipto, \& Kosasi, R. (2009). Profesi Keguruan. Jakarta: Rineka Cipta.

Sudrajat. (2007). Kartini: Perjuangan dan Pemikirannya. Dari: http:/ / download.portalgaruda.org/article.php?article=354121\&

Tafsir, ahmad. (2012). Ilmu Pendidikan Islami. Bandung: PT Remaja Rosdakarya.

Undang-Undang Nomor 20 Tahun 2003 tentang Sistem Pendidikan Nasional

V. Good, Carter dan Winifred R. Markel. (1973). Dictionary of Education. New York: McGraw-Hill

Vreede-De Stuers, Cora. (2017). Sejarah Perempuan Indonesia Gerakan dan Pencapaian. Depok: Komunitas Bambu.

Wiriaatmadja, Rochiati. (1985). Dewi Sartika. Jakarta: Departemen Pendidikan dan Kebudyaan.

Zakiah, Lina. (2011). Konsep Pendidikan Perempuan Menurut Raden Dewi Sartika. Skripsi Tidak Diterbitkan. Dari: http:/ / repository.uinjkt.ac.id/dspace/ bitstream/123456789/1647/1/101872LINA\%20ZAKIAH-FITK.pdf 